\title{
ON A SPONGE DESTRUCTIVE TO OYSTER CULTURE IN THE CLARENCE RIVER.
}

\author{
By R. von Lendenfeld, Ph.D.
}

I was lately instructed by the Commissioners of Fisheries, to report on a sponge injurious to oyster culture in the Ciarence River. Some of the facts noticed in this report are here mentioned, as I think they will be of general interest.

The locality which was affected and which I was to report upon, I did not personally visit, and the information and specimens on which my report was founded were derived entirely from $\mathrm{Mr}$. Woodward, the intelligent lessee of the oyster beds in question.

The whole nearly of that part of the bed of Clarence River, which is situated in proximity to a lake, and also a portion of the lake itself, was covered five years ago by an extensive oyster bed.

In a small portion of this area, where the river jo ns the lake, four years ago an overgrowth made its appearance, which smothered all the oysters and prevented the setting of the spat. Consequently no oysters have been procured from this area during the last few years, whilst formerly the same area yielded, as I have been informed, thousands of sacks. The lessee ascribed this to the existence of the overgrowth mentioned above.

I have examined specimens of it, and have found that it is a sponge belonging to a species new to science. The sponge grows on the outer side of oyster shells, which in that locality form the bottom.

The sponge consists of numerous flattened, finger-shaped processes joined at the base to form a bulky mass. The color is light brown. The size of the largest specimens seen by me is $7^{\prime \prime} \times 3^{\prime \prime} \times 4^{\prime \prime}$.

The finger-shaped processes attain a length of 4 " and a diameter of $\frac{3}{4}$ of an inch. They terminate either with a rounded cone or show a tendency to bifurcation near the termination. 
The surface of the sponge is smooth, here and there smal apertures with a circular circumference and a diameter of 0.1 inch occur. These are slightly raised above the general surface of the sponge, and more numerous towards the tips of the finger-shaped processes than in other parts.

The base of the sponge adheres very rigidly to the oyster shell.

The microscopic investigation reveals a skeleton, consisting of a network of exceedingly slender, anastomosing threads, consisting of dense masses of silicious spicules.

The spicules are simple, rod-shaped, slightly bent and pointed abruptly at each end, the outer apparently smooth surface is pervaded by numerous pores closed externally by a sieve with extremely fine perforations.

These holes lead into extensive lacunose sub-dermal cavities from whence canals originate, which extend in a centripetal direction, and which continually ramify, supplying small ciliated chambers situated in the interior. From these other canals originate, which unite to form wide oscular tubes.

It appears that five years ago this sponge did not occur in the locality, that afterwards the sponges made their appearance and killed the oysters thereon, and covered that area with a dense growth of sponges, standing so close to one another, that there was no room for the oysters between them.

The most interesting fact however, is that now since all the oysters have died out, the sponge is likewise disappearing, and great patches of the bottom in that locality are already clean.

It appears from the above that the sponge described, which I have named Chalinula Coxii, grows on the shells of living oysters, but disappears after the oysters are dead, and further, that the sponge exerts some direct influence on the oysters, which is so detrimentary to the latter that they die.

There is certainly no direct connection between the oyster animal and the sponge whatever, as the sponge only adheres to the outer surface of the shell. 
That the sponge does not draw its nourishment, as a parasite would, from the oyster animal, can also be demonstrated by the fact, that the sponge grows on other submerged bodies besides the oyster shell.

The sponge can therefore on no account have a direct effect on the old oysters.

The sponge might, however, perhaps have a detrimentary effect in an indirect manner.

Both the sponge and the oyster live on microscopic particles of a digestable nature.

The sponge overgrowing the oyster will therefore intercept and retain a great portion of that food, the whole of which would, were the sponge not present, be available for the oyster. The sponge takes the food away from the oyster and thrives at the expense of the latter.

In this way the sponge will have a bad effect on adult oysters, but in no other. It appears clear, however, that the sponge will, where it is dominant, prevent the setting of the spat, as the spat cannot set on the sponge itself and the sponge takes up the whole of the area. I think that these conclusions will satisfactorily explain the facts observed.

The sponge settled on the oyster bed and spread there rapidly taking up all the space. The spat could not set. The old oysters died for want of nourishment and finally no live oysters remained in the locality.

The fact that the sponges are now again disappearing shows that they depend to a certain extent, probably, on the oysters.

Around the oysters always a superabundance of microscopic animals congregate, which feed on the excrements of the oysters, and it is probable that the sponges lived to a great extent on them.

Some species of sponges are found only in water with strong currents, and it seems not improbable that that is also the case with our Chalinula Coxii. In the locality where the sponges have taken possession of the oyster bed the channel is narrower and shallower than it is in other parts, and consequently the currents in that part must be stronger than elsewhere, 


\section{Remedy.}

In the oyster beds along the shores of the Mediterranean, sponges of various kinds, especially species of the genus of Euspongia, sometimes smother the oysters in a similar manner as has been observed in the Clarence.

In Trieste the oysters are grown on submerged trees, on which the spat readily sets and which are taken from the water and divested of their marine fruit as required.

It sometimes occurs that sponges grow on these oyster-trees. The effective remedy against these sponges is to take the tree from the water during rain.

The fresh water kills all the sponges in a few hours during which period the oysters are of course not at all affected by being out of the sea. The tree is, after several hours, placed in the sea water again and the sponges rot and fall off. In our case such a remedy can of course not be employed.

The only suggestion which seems possible is to lead fresh water through pipes to the infected locality, and in this way gradually kill all the sponges. 


\section{$2 \mathrm{BHL}$ Biodiversity Heritage Library}

Lendenfeld, R. von. 1885. "On a sponge destructive to oyster culture in the Clarence River." Proceedings of the Linnean Society of New South Wales 10, 326-329. https://doi.org/10.5962/bhl.part.17930.

View This Item Online: https://www.biodiversitylibrary.org/item/30482

DOI: https://doi.org/10.5962/bhl.part.17930

Permalink: https://www.biodiversitylibrary.org/partpdf/17930

\section{Holding Institution}

MBLWHOI Library

\section{Sponsored by}

MBLWHOI Library

\section{Copyright \& Reuse}

Copyright Status: NOT_IN_COPYRIGHT

This document was created from content at the Biodiversity Heritage Library, the world's largest open access digital library for biodiversity literature and archives. Visit BHL at https://www.biodiversitylibrary.org. 